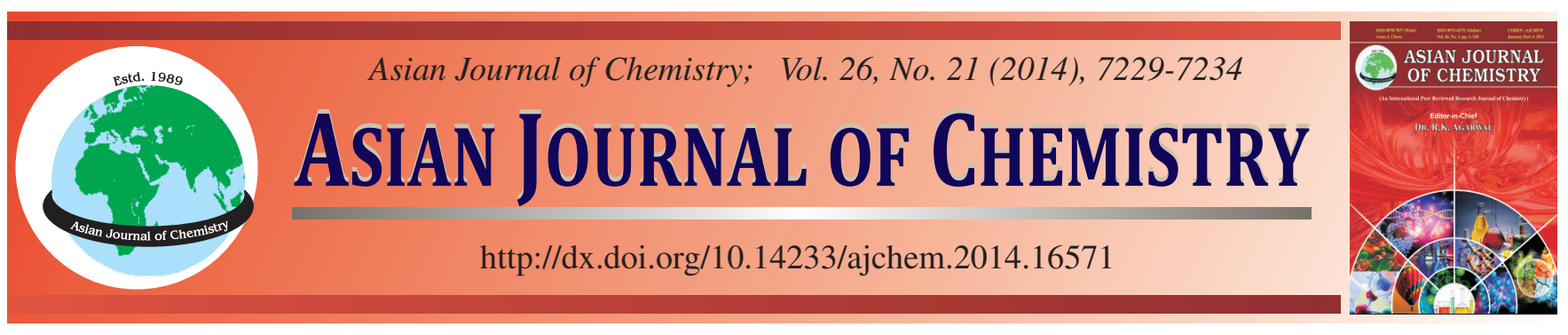

\title{
Highly Sensitive Cobalt Porphyrin Biomimetic Catalyzed Flow Injection Chemiluminescence Determination of Diethylstilbestrol in Pharmaceuticals
}

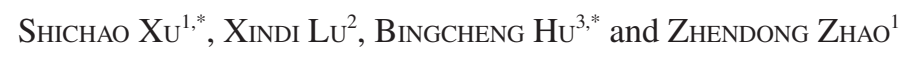

${ }^{1}$ Institute of Chemical Industry of Forestry Products, CAF; National Engineering Lab. for Biomass Chemical Utilization; Key and Open Lab. on Forest Chemical Engineering, SFA; Key Lab. of Biomass Energy and Material, Jiangsu Province, Nanjing 210042, P.R. China

${ }^{2}$ Zhuzhou Sonbon Forest Chemical Co. LTD, Zhuzhou 412001, P.R.China

${ }^{3}$ College of Chemical Engineering, Nanjing University of Science and Technology, Nanjing 210094, P.R. China

*Corresponding authors: Tel: +86 25 85482451; E-mail: toughxu@ 163.com; Tel: +86 25 84315030; E-mail: hubingcheng210094@ 163.com

The great inhibition of diethylstilbestrol to cobalt deuteroporphyrin catalyzed luminol- $\mathrm{H}_{2} \mathrm{O}_{2}$ chemiluminescence reaction, has been exploited to develop a novel and sensitive flow-injection chemiluminescence detection method for the determination of diethylstilbestrol. The optimum experimental conditions and the possible mechanism have been investigated. Under the optimized parameters, the relative chemiluminescence intensity is linearly related to the concentration of diethylstilbestrol in the range of $6 \times 10^{-10}-1.0 \times 10^{-8} \mathrm{~g} \mathrm{~mL}^{-1}$ and $1 \times 10^{-8}-1 \times 10^{-7} \mathrm{~g} \mathrm{~mL}^{-1}$ with a detection limit of $3.83 \times 10^{-10} \mathrm{~g} \mathrm{~mL}^{-1}$. The proposed method could be successfully applied to the determination of diethylstilbestrol in pharmaceuticals.

Keywords: Luminol, Cobalt porphyrin, Diethylstilbestrol determination, Chemiluminescence.

\section{INTRODUCTION}

As one of the most important synthetic estrogen hormones, diethylstilbestrol has been found to be the most potent endocrine disruption chemical ${ }^{1}$. Thus, it can be used as a treatment for postcoital contraception or estrogen-deficiency disorders ${ }^{2}$. However, clinical and experimental studies have revealed that the toxicity of diethylstilbestrol is severe due to its slow degradation rate in the body and its carcinogenic properties and other adverse effects ${ }^{3,4}$. Therefore, it is vital to develop simple and accurate methods for quantitative analysis of diethylstilbestrol to guarantee the quality of its products and ensure the safe use of its associated pharmaceuticals.

Several methods, such as gas/liquid chromatography (GC/LC) detection ${ }^{5}$ GC/LC-mass spectrometry detection ${ }^{6,7}$ diode array detector (DAD) or DAD-mass spectrometry detection $^{8}$ and fluoroimmunoassay detection ${ }^{2}$ have been reported for the determination of diethylstilbestrol. Although every method has its own advantages, most of the reported protocols are instrument-expensive, approach-complicated and timeconsuming. As a rapid and simple method with inexpensive instruments, flow-injection chemiluminescence (FI-CL) systems have received much attention in analysis applications because of their high sensitivity, fast kinetics and good accuracy ${ }^{9,10}$. Among them, enzymes catalyzed luminol- $\mathrm{H}_{2} \mathrm{O}_{2}$ system is one of the most efficient chemiluminescence systems, but the instability and high cost of them has stimulated people to search for alternatives ${ }^{11}$.

Metalloporphyrin complexes are important $18 \pi$-conjugated organic molecules and have been extensively used in a variety of chemical, biological and clinical studies to mimic the active sites of enzymes ${ }^{12}$. Metalloporphyrin complexes have been widely used as a substitute for enzymes in several chemiluminescence systems for analysis applications, but most are based on totally synthetic metallo-tetraarylporphyrins (MTPPs) or naturally occurred metalloporphyrins ${ }^{13,14}$. The use of semisynthetic metalloporphyrins is rarely reported ${ }^{11}$ especially in the determination of diethylstilbestrol. In our previous work, semi-synthetic manganese deuteroporphyrin (MnDP) was found to be an active catalysis in biomimic catalyzed luminol$\mathrm{H}_{2} \mathrm{O}_{2}$ chemiluminescence system ${ }^{11}$. However, among all the studies on metalloporphyrin-catalyzed oxidations, cobalt porphyrins (CoPs) are always the first choice because of their higher catalytic activity than their other metal complexes ${ }^{15}$. These facts led us to consider that cobalt deuteroporphyrin (Scheme-I, II) should play an important role in biomimic catalyzed chemiluminescence reactions.

In our preliminary experiments, the inhibition of diethylstilbestrol to the weak emission of luminol- $\mathrm{H}_{2} \mathrm{O}_{2}$ chemiluminescence system was found to be greatly enhanced by cobalt 
deuteroporphyrin. Based on this reaction, we developed a novel and simple FI-CL method for the determination of diethylstilbestrol with high sensitivity and selectivity. The role of cobalt deuteroporphyrin in this reaction and the possible reaction mechanism were also discussed in this paper. To the best of our knowledge, this is the first report on the use of cobalt deuteroporphyrin in chemiluminescence analysis for the determination of diethylstilbestrol.

\section{EXPERIMENTAL}

Melting points were obtained from a Kofler hot-stagemicroscope apparatus and were uncorrected (Reichert, Austria). ${ }^{1} \mathrm{H}$ NMR spectra were determined on a Bruker Avance III 500 $\mathrm{MHz}$ spectrometer using DMSO- $d_{6}$ as solvent and tetramethylsilane as internal standard (Bruker, German). IR spectra were recorded on a Thermo Nicolte IS10 IR instrument using attenuated total reflection method (Thermo, America). ESIMS/MS spectra were measured on a Finnigan TSQ Quantum ultra AM mass spectrometer with an electrospray ionization source (Finnigan, America). Elemental analysis was performed on a PE-2004 elemental analyzer (Perkin-Elmer, America). The UV-visible spectra were completed on a Lambda-35 UVspectrofluorimeter (Perkin-Elmer, America). FI-CL measurements were run using a model IFFM-E FI-CL analysis system (Ruimai Electronic Science Co., China). The kinetic curve and luminescence spectra were carried out on a RF-5301pc spectrofluorometer (Shimadzu, Japan).

All chemical reagents were of analytical grade obtained from commercial sources and used without further purification. Double-distilled water was used throughout the work. Deuteroporphyrin (Scheme-I, II) was synthesized, purified and characterized from hemin (1) according to previous work $^{15,16}$. Cobalt was introduced into porphyrin centre similarly to the manganese insertion method ${ }^{11}$. In brief: $0.46 \mathrm{~g}$ deuteroporphyrin $(0.90 \mathrm{mmol})$ was added to $30 \mathrm{~mL}$ DMF in a $150 \mathrm{~mL}$ three-neck-flask. The mixture was heated to reflux under continuous magnetic stirring and then $0.6 \mathrm{~g} \mathrm{CoCl}_{2} \cdot 6 \mathrm{H}_{2} \mathrm{O}(2.52$ mmol) was added. The mixture was stirred under reflux for $0.5 \mathrm{~h}$ and then cooled to room temperature and transformed into a $600 \mathrm{~mL}$ beaker. $500 \mathrm{~mL}$ water was added to crystallize the product. The precipitates were collected, washed with water for three times and dried in vacuum. m.p. $>300{ }^{\circ} \mathrm{C} ;{ }^{1} \mathrm{H}$ NMR: paramagnetic; IR $\left(\mathrm{KBr}, \mathrm{v}_{\max }, \mathrm{cm}^{-1}\right): 2926\left(\mathrm{~m}, \mathrm{v}_{\mathrm{C}-\mathrm{H}}\right), 1705(\mathrm{~s}$, $\left.\mathrm{v}_{\mathrm{C}=\mathrm{O}}\right), 1552\left(\mathrm{~m}, \delta_{\mathrm{NH}}\right), 1340(\mathrm{~m}), 1310(\mathrm{~m}), 1112\left(\mathrm{~s}, \mathrm{v}_{\mathrm{C}-\mathrm{O}}\right), 1029$ (s), 984 (m), 893 (w), 849 (m), 755 (m); ESI+-MS (35 eV, $\mathrm{m} / \mathrm{z}): 567[\mathrm{M}]^{+}, 508\left[\mathrm{M}-\mathrm{CH}_{2} \mathrm{CO}_{2} \mathrm{H}\right]^{+}, 449\left[\mathrm{M}-2 \mathrm{CH}_{2} \mathrm{CO}_{2} \mathrm{H}\right]^{+}$.

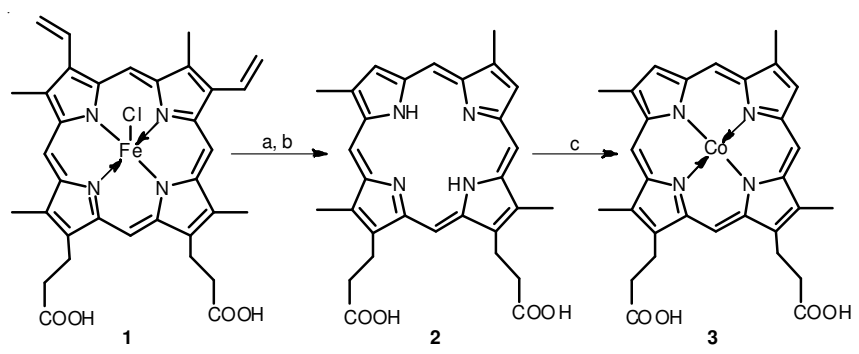

Scheme-I: Synthesis of cobalt deuteroporphyrin; (a) $\mathrm{C}_{6} \mathrm{H}_{6} \mathrm{O}_{2},\left(\mathrm{CH}_{3} \mathrm{CH}_{2}\right)_{2} \mathrm{O}$, $160{ }^{\circ} \mathrm{C}, 4 \mathrm{~h}$; (b) $\left(\mathrm{CH}_{3} \mathrm{CO}\right)_{2} \mathrm{O}, \mathrm{FeSO}_{4}, \mathrm{HCl}_{(\mathrm{aq})}, 100{ }^{\circ} \mathrm{C} 2 \mathrm{~h}$; (c) DMF, $\mathrm{CoCl}_{2} \times 6 \mathrm{H}_{2} \mathrm{O}$, reflux, $2 \mathrm{~h}$
The stock solution of $5 \times 10^{-4} \mathrm{~g} \mathrm{~mL}^{-1}$ luminol (SigmaAldrich) was prepared by dissolving $0.05 \mathrm{~g}$ luminol in 100 $\mathrm{mL}$ of $0.01 \mathrm{~mol} \mathrm{~L}^{-1} \mathrm{NaOH}$ solution in a brown flask. Stock standard solution of $1 \times 10^{-4} \mathrm{~g} \mathrm{~mL}^{-1}$ diethylstilbestrol (SigmaAldrich) was prepared by dissolving $0.01 \mathrm{~g}$ diethylstilbestrol in $100 \mathrm{~mL} 0.05 \mathrm{~mol} \mathrm{~L}^{-1} \mathrm{NaOH}$ solution in a brown flask to avoid light decomposition. The stock solution of $3 \times 10^{-5} \mathrm{~g}$ $\mathrm{mL}^{-1}$ cobalt deuteroporphyrin was prepared by dissolving $0.0075 \mathrm{~g}$ of cobalt deuteroporphyrin in $250 \mathrm{~mL} 0.05 \mathrm{~mol} \mathrm{~L}^{-1}$ $\mathrm{NaOH}$ solution. The $0.4 \mathrm{~mol} \mathrm{~L}-1$ stock solution of $\mathrm{H}_{2} \mathrm{O}_{2}$ was prepared by diluting $2 \mathrm{~mL}$ of $30 \% \mathrm{H}_{2} \mathrm{O}_{2}$ to $50 \mathrm{~mL}$ in a brown flask. $4 \mathrm{~mol} \mathrm{~L}^{-1} \mathrm{NaOH}$ stock solution was prepared by diluting $40 \mathrm{~g} \mathrm{NaOH}$ in $250 \mathrm{~mL}$ water. All stock solutions were kept in a refrigerator $\left(4^{\circ} \mathrm{C}\right)$ and diluted daily as required before use.

Analytical procedures: As shown in Fig. 1, the flowinjection analysis manifold used throughout this study was composed of two peristaltic pumps. One delivered diethylstilbestrol (a), cobalt deuteroporphyrin (b) and $\mathrm{NaOH}$ (c) solutions at a flow rate of $3 \mathrm{~mL} \mathrm{~min}^{-1}$. The other delivered luminol (d) and $\mathrm{H}_{2} \mathrm{O}_{2}$ (e) solutions at a flow rate of $2.5 \mathrm{~mL} \mathrm{~min}^{-1}$. All components in the flow system were connected by $0.8 \mathrm{~mm}$ (i.d.) polytetrafluoroethylene tubes. The solutions merged in each pumps were mixed through the Y-shape element, which was positioned just before the flow cell inlet. The flow cell was a coil of $1.3 \mathrm{~mm}$ (i.d.) glass tube spiraled to a diameter of $35 \mathrm{~mm}$ with 5 turns and was located in front of the detection window of photomultiplier tubes (PMTs). The emitted chemiluminescence was collected and converted by photomultiplier tubes to current signals and recorded with a computer via special software ${ }^{17,18}$. In order to obtain good stability, the instruments were run until a stable baseline was recorded before the first measurement.

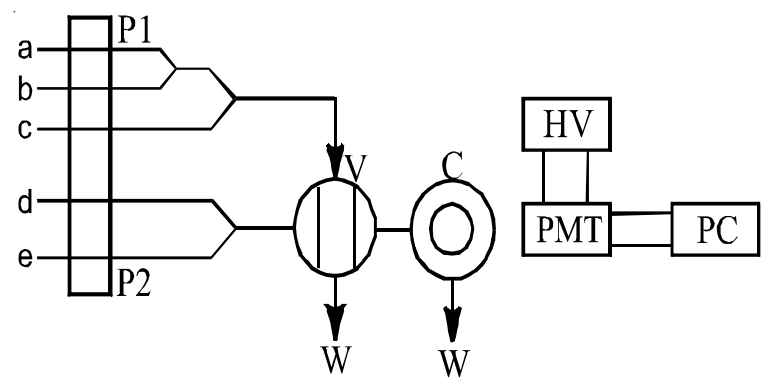

Fig. 1. Schematic diagram of FI-CL system; (a) diethylstilbestrol or sample solution; (b) cobalt deuteroporphyrin solution; (c) $\mathrm{NaOH}$ solution; (d) luminol solution; (e) $\mathrm{H}_{2} \mathrm{O}_{2}$ solution; (P) peristaltic pump; (V) injection valve; (C) flow cell; (W) waste; (HV) high negative voltage; (PMT) photomultiplier tube; (PC) personal computer

Determination of diethylstilbestrol in pharmaceutical preparations: Ten tablets of diethylstilbestrol were weighed, finely powdered and homogenized. An accurately amount of the powder (equivalent to the weight of a tablet) was dissolved with $40 \mathrm{~mL}$ ethanol. The resulting suspension was ultrasonically dispersed for $1 \mathrm{~h}$. The solution was filtered and the residue was washed with ethanol for several times. The organic phase was collected and evaporated to dryness by a rotatory evaporator. The dry residue was dissolved with $100 \mathrm{~mL}$ of $0.05 \mathrm{~mol} \mathrm{~L}^{-1} \mathrm{NaOH}$ solution and used as the sample solution. The obtained sample was determined similar to the determination procedures of diethylstilbestrol standard solution described above. 


\section{RESULTS AND DISCUSSION}

Kinetic curves of this chemiluminescence reaction in the presence and absence of diethylstilbestrol were investigated with a static method. The curves in Fig. 2 indicate that this system shows a fast-type luminescence. The chemiluminescence intensity reached a maximum value within $2.2 \mathrm{~s}$ after the addition of hydrogen peroxide and the chemiluminescence signals decreased to the baseline within $15 \mathrm{~s}$. Compared with that without diethylstilbestrol (Fig. 2b), the emission intensity is significantly restrained. The kinetic curves manifest that this system is very suitable for FI-CL determination of diethylstilbestrol.

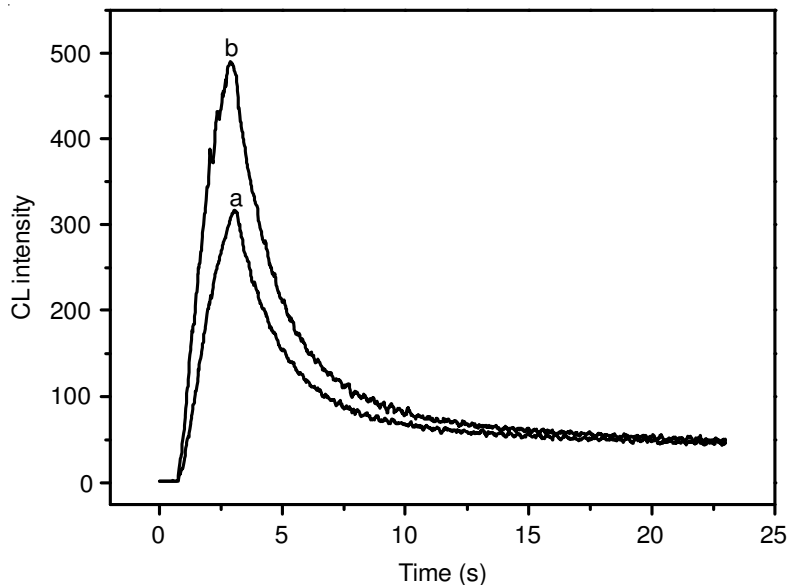

Fig. 2. Kinetic curves of chemiluminescence systems: (a) luminol + cobalt deuteroporphyrin $+\mathrm{H}_{2} \mathrm{O}_{2}+\mathrm{NaOH}$; (b) diethylstilbestrol + luminol + cobalt deuteroporphyrin $+\mathrm{H}_{2} \mathrm{O}_{2}+\mathrm{NaOH}$
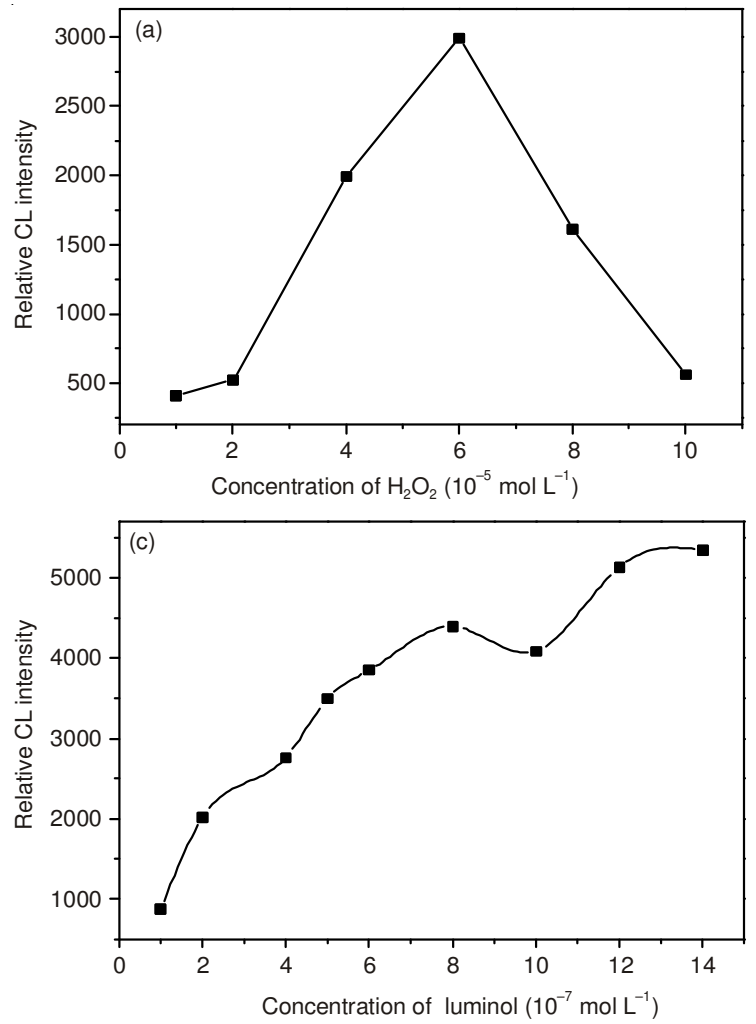

Effect of $\mathrm{H}_{2} \mathrm{O}_{2}$ concentration: $\mathrm{H}_{2} \mathrm{O}_{2}$ was the chemiluminescence oxidant in luminol- $\mathrm{H}_{2} \mathrm{O}_{2}$ chemiluminescence system and could influence the chemiluminescence intensity evidently. The effect of $\mathrm{H}_{2} \mathrm{O}_{2}$ concentration in the range $8 \times 10^{-6}$ to $1 \times$ $10^{-4} \mathrm{~mol} \mathrm{~L}^{-1}$ on the chemiluminescence intensity has been examined (Fig. 3a). It was found that the relative chemiluminescence intensity increased with the increasing of $\mathrm{H}_{2} \mathrm{O}_{2}$ concentration and got a maximum at $6 \times 10^{-5} \mathrm{~mol} \mathrm{~L}^{-1}$. The relative chemiluminescence intensity would glissade in both sides with $\mathrm{H}_{2} \mathrm{O}_{2}$ concentration changed. Thus, $6 \times 10^{-5} \mathrm{~mol} \mathrm{~L}^{-1} \mathrm{H}_{2} \mathrm{O}_{2}$ was chosen as the optimum concentration in this study.

Effect of $\mathrm{NaOH}$ concentration: It is widely reported that luminol can be greatly stabilized by protonation ${ }^{19}$. Thus, the alkalinity of reaction medium has great influence on the reaction. The influence of $\mathrm{NaOH}$ concentration on the chemiluminescence reaction of luminol was studied. As shown in Fig. $3 b$, the relative chemiluminescence intensity increased with the increasing $\mathrm{NaOH}$ concentration from 0.2 to $0.4 \mathrm{~mol}$ $\mathrm{L}^{-1}$ and reached its maximum value at the $\mathrm{NaOH}$ concentration of $0.4 \mathrm{~mol} \mathrm{~L}^{-1}$. When the concentration of $\mathrm{NaOH}$ was higher than $0.4 \mathrm{~mol} \mathrm{~L}^{-1}$, the relative chemiluminescence intensity decreased with the increase of the concentration of $\mathrm{NaOH}$. Therefore, $0.4 \mathrm{~mol} \mathrm{~L}^{-1} \mathrm{NaOH}$ was chosen for further experiments.

Effect of luminol concentration: In this chemiluminescence system, the concentration of luminant can influence the signal magnitude obviously. The effect of luminol concentration on the chemiluminescence signal was examined in the range of $1 \times 10^{-7}-1.4 \times 10^{-6} \mathrm{~g} \mathrm{~mL}^{-1}$ (Fig. $3 \mathrm{c}$ ). The results indicate
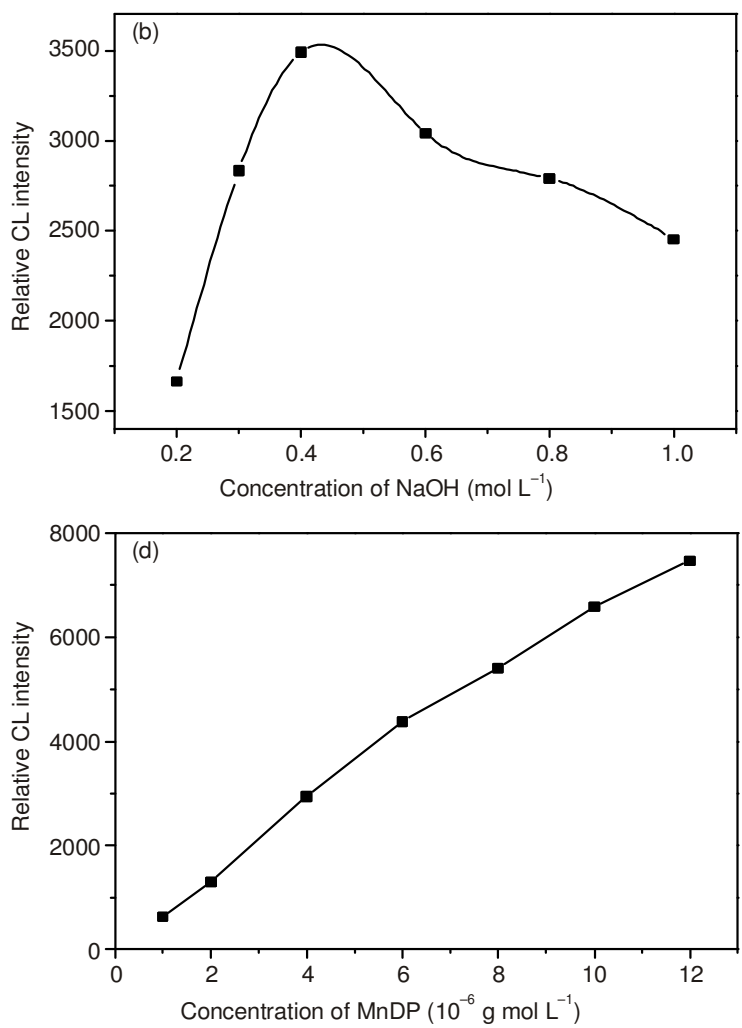

Fig. 3. Effect of concentrations of $\mathrm{NaOH}(\mathrm{a}), \mathrm{H}_{2} \mathrm{O}_{2}$ (b), luminol (c) and cobalt deuteroporphyrin (d) on the chemiluminescence intensity. (a) concentrations: $\left[\mathrm{NaOH}\right.$ ], $0.6 \mathrm{~mol} \mathrm{~L}^{-1}$; [luminol], $5 \times 10^{-7} \mathrm{~g} \mathrm{~mL}^{-1}$; [cobalt deuteroporphyrin], $5 \times 10^{-6} \mathrm{~g} \mathrm{~mL}^{-1}$; [diethylstilbestrol], $1 \times 10^{-8} \mathrm{~g} \mathrm{~mL}^{-1}$; (b) concentrations: $\left[\mathrm{H}_{2} \mathrm{O}_{2}\right.$ ], $6 \times 10^{-5} \mathrm{~mol} \mathrm{~L}^{-1}$; [luminol], $5 \times 10^{-7} \mathrm{~g} \mathrm{~mL}^{-1}$; [cobalt deuteroporphyrin], $5 \times 10^{-6} \mathrm{~g} \mathrm{~mL}^{-1}$; [diethylstilbestrol], $1 \times 10^{-8} \mathrm{~g} \mathrm{~mL}^{-1}$; (c) concentrations: [NaOH], $0.6 \mathrm{~mol} \mathrm{~L} \mathrm{~N}^{-1} ;\left[\mathrm{H}_{2} \mathrm{O}_{2}\right.$ ], $6 \times 10^{-5} \mathrm{~mol} \mathrm{~L}^{-1}$; [cobalt deuteroporphyrin], $5 \times 10^{-6} \mathrm{~g} \mathrm{~mL}^{-1}$; [diethylstilbestrol], $1 \times 10^{-8} \mathrm{~g} \mathrm{~mL}{ }^{-1}$; (d) concentrations: $[\mathrm{NaOH}], 0.6 \mathrm{~mol} \mathrm{~L}^{-1} ;\left[\mathrm{H}_{2} \mathrm{O}_{2}\right.$ ], $6 \times 10^{-5} \mathrm{~mol} \mathrm{~L}^{-1}$; [luminol], $5 \times 10^{-7} \mathrm{~g} \mathrm{~mL}^{-1}$; [diethylstilbestrol], $1 \times 10^{-8} \mathrm{~g} \mathrm{~mL}^{-1}$ 
that the relative chemiluminescence intensity increases with the increase of luminol concentration in the range of $1 \times 10^{-7}$ $-8 \times 10^{-7}$ and $1 \times 10^{-6}-1.4 \times 10^{-6} \mathrm{~g} \mathrm{~mL}^{-1}$. However, the chemiluminescence intensity of the blank chemiluminescence intensity becomes very strong when the concentration of luminol is higher than $8 \times 10^{-7} \mathrm{~g} \mathrm{~mL}^{-1}$ and leads to poor reproducibility. Considering the chemiluminescence intensity and the experimental reproducibility, $8 \times 10^{-7} \mathrm{~g} \mathrm{~mL}^{-1}$ luminol was adopted as the optimal concentration for further use.

Effect of cobalt deuteroporphyrin concentration: The amount of catalyst is an important factor influencing signal intensities in catalyzed chemiluminescence reactions. The effect of cobalt deuteroporphyrin concentration was investigated in the range from $1 \times 10^{-6}$ to $1.2 \times 10^{-5} \mathrm{~g} \mathrm{~mL}^{-1}$ and the results are shown in Fig. 3d. From Fig. 3d, the relative chemiluminescence intensity was found to increase with increasing cobalt deuteroporphyrin concentration in the whole range. Considering the sensitivity and saving reagents, $6 \times 10^{-6} \mathrm{~g} \mathrm{~mL}^{-1}$ was selected as the optimal concentration in the following study.

Effect of flow rate: As an important parameter in FT-CL system, flow rate might influence the intensity of chemiluminescence signal and the analytical sensitivity. Unsuitable flow rate results in the decrease or even the disappearing of chemiluminescence signal. In order to obtain satisfactory emission intensity, the effect of flow rate on chemiluminescence intensity was studied over the range 0.5 to $4.5 \mathrm{~mL} \mathrm{~min}^{-1}$ in each stream. The results indicate that the chemiluminescence intensity increased with increasing flow rate of diethylstilbestrol, cobalt deuteroporphyrin and $\mathrm{NaOH}$ up to $3 \mathrm{~mL} \mathrm{~min}^{-1}$ and luminol and $\mathrm{H}_{2} \mathrm{O}_{2}$ up to $2.5 \mathrm{~mL} \mathrm{~min}^{-1}$. Thus, flow rate of $3 \mathrm{~mL}$ $\min ^{-1}$ and $2.5 \mathrm{~mL} \mathrm{~min}^{-1}$ were chosen for further studies.

Analytical performance: Under the optimized experimental conditions selected above, the calibration graph of the relative chemiluminescence intensity $v s$. the concentration of diethylstilbestrol was linear in the range of diethylstilbestrol $6 \times 10^{-10}-1 \times 10^{-8} \mathrm{~g} \mathrm{~mL}^{-1}$ and $1 \times 10^{-8}-1 \times 10^{-7} \mathrm{~g} \mathrm{~mL}^{-1}$ with the regression equation $\Delta \mathrm{I}=54.80+8.70 \times 1010 \mathrm{c}(\mathrm{r}=0.9905)$ and $\Delta \mathrm{I}=861.64+2.41 \times 1010 \mathrm{c}(\mathrm{r}=0.9928)$, respectively. The detection limit $(3 \sigma)$ was $3.83 \times 10^{-10} \mathrm{~g} \mathrm{~mL}^{-1}$ and the relative standard deviation for $5 \times 10^{-8} \mathrm{~g} \mathrm{~mL}^{-1}$ diethylstilbestrol was $2.64 \%(\mathrm{n}=11)$.

Interference: In order to evaluate the selectivity of this system, the effects of some possibly co-existing inorganic ions, organic molecules and biomolecules on the determination of diethylstilbestrol by the developed method were examined using a standard solution of diethylstilbestrol $\left(5 \times 10^{-8} \mathrm{~g} \mathrm{~mL}^{-1}\right)$ into which increasing amount of interfering analytes were added. The tolerable limit was taken as it caused a relative error not greater than $\pm 5 \%$. The results indicated that no interference was found with $\mathrm{K}^{+}, \mathrm{Na}^{+}$and $\mathrm{CO}_{3}{ }^{2-}$ at 5000 times the concentration of diethylstilbestrol, $\beta$-cyclodextrin at less than 1500 times the concentration of diethylstilbestrol, $\mathrm{Br}^{-}$ and glucose at less than 200 times the concentration of diethylstilbestrol, $\mathrm{Ba}^{2+}, \mathrm{I}^{-}$and L-tryptophan at less than 90 times the concentration of diethylstilbestrol, $\mathrm{Mn}^{2+}$ and $\mathrm{Mg}^{2+}$ at less than 40 times the concentration of diethylstilbestrol, $\mathrm{Zn}^{2+}, \mathrm{PO}_{4}{ }^{3-}$ and protein at less than 10 times the concentration of diethylstilbestrol and $\mathrm{Fe}^{3+}$ at less than 2 times the concentration of diethylstilbestrol. Thus, the exploited chemiluminescence system had an excellent specificity for the highly sensitive detection of diethylstilbestrol without sample pretreatment.

Applications: The proposed method was applied to determine diethylstilbestrol in commercial pharmaceutical samples. The samples were treated and determined as described in "Determination of diethylstilbestrol in pharmaceutical preparations". The determination results and the recovery of standard addition were obtained and summarized in Table-1. It could be seen that the accuracy and precision of the proposed method were satisfactory.

\begin{tabular}{|c|c|c|c|c|c|c|c|}
\hline & $\begin{array}{r}\text { DETERM } \\
\text { COMMH }\end{array}$ & $\begin{array}{l}\text { IINATI } \\
\text { ERCIA }\end{array}$ & $\begin{array}{r}\mathrm{T} \\
\mathrm{N} \mathrm{OF} \\
\mathrm{PHAI}\end{array}$ & $\begin{array}{l}\text { BBLE-1 } \\
\text { DIETHYL } \\
\text { MACEUT }\end{array}$ & $\begin{array}{l}\text { TILBE } \\
\text { CAL S }\end{array}$ & $\begin{array}{l}\text { ROL IN } \\
\text { PLES }\end{array}$ & \\
\hline Sample & $\begin{array}{l}\text { Specific. } \\
\text { (mg/tablet) }\end{array}$ & $\begin{array}{l}\text { Found } \\
\text { (mg) }\end{array}$ & $\begin{array}{c}\text { RSD } \\
(\%, \\
\mathrm{n}=7)\end{array}$ & $\begin{array}{c}\text { Added } \\
\left(\times 10^{-8} \mathrm{~g}\right. \\
\left.\mathrm{mL}^{-1}\right)\end{array}$ & $\begin{array}{c}\text { Found } \\
\left(\times 10^{-8} \mathrm{~g}\right. \\
\left.\mathrm{mL}^{-1}\right)\end{array}$ & $\begin{array}{c}\text { Recovery } \\
(\%)\end{array}$ & $\begin{array}{c}\text { RSD } \\
(\%, \\
n=7)\end{array}$ \\
\hline & & & & 3 & 2.90 & 96.7 & 1.84 \\
\hline $1^{\mathrm{a}}$ & 0.5 & 0.491 & 2.78 & 4 & 4.06 & 101.5 & 2. \\
\hline & & & & 5 & 4 & 97.6 & 1. \\
\hline & & & & 3 & 3.02 & 100.7 & 1.97 \\
\hline $2^{b}$ & 1.0 & 0.973 & 2.14 & 4 & 4.1 & 103.5 & 2.45 \\
\hline & & & & 5 & 4.81 & 96.2 & 1.18 \\
\hline
\end{tabular}

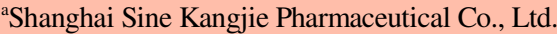

${ }^{\mathrm{b}}$ Hefei Jiulian Pharmaceutical Co., Ltd.

Possible chemiluminescence mechanisms: In order to explore the possible mechanism of this chemiluminescence reaction, the effect of cobalt deuteroporphyrin to this cobalt deuteroporphyrin-luminol- $\mathrm{H}_{2} \mathrm{O}_{2}$ system was obtained using a Lambda-35 UV-spectrofluorimeter and a RF-5301pc spectrofluorimeter. The obtained UV-visible spectra and chemiluminescence spectra are shown in Figs. 4 and 5, respectively. The UV-visible spectra show that the absorption intensity of the mixed system is equal to the sum of two individual systems. Therefore, we suggest no reaction occurred between luminol and cobalt deuteroporphyrin.

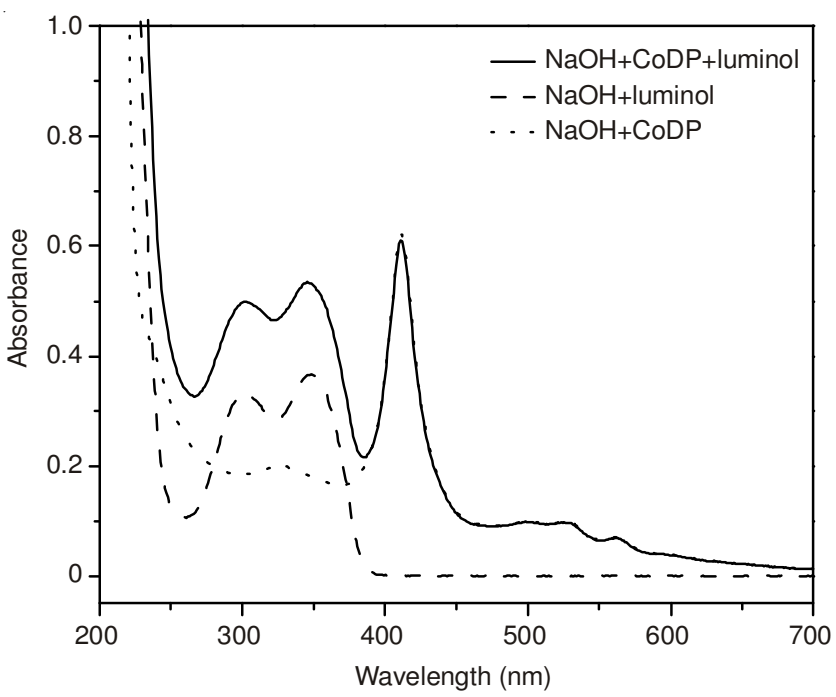

Fig. 4. UV-visible absorption spectra of cobalt deuteroporphyrin, luminol, cobalt deuteroporphyrin-luminol in $\mathrm{NaOH}$ solution. Concentrations: [NaOH] $0.4 \mathrm{~mol} \mathrm{~L}{ }^{-1}$; [luminol], $4 \times 10^{-5} \mathrm{~mol} \mathrm{~L}^{-1}$; [cobalt deuteroporphyrin], $6 \times 10^{-6} \mathrm{~g} \mathrm{~mL}^{-1}$ 
The chemiluminescence spectra as depicted in Fig. 5 show that the oxidation of luminol by $\mathrm{H}_{2} \mathrm{O}_{2}$ in absence of cobalt deuteroporphyrin solution is a relatively slow reaction process because the chemiluminescence intensity is relatively weak. However, the relative chemiluminescence intensity of luminol in presence of cobalt deuteroporphyrin is greatly enhanced attributed to the catalysis of cobalt deuteroporphyrin to the oxidation of luminol, which obviously indicates that cobalt deuteroporphyrin play a key role in this chemiluminescence reaction. The maximum emission wavelength in the chemiluminescence spectra of luminol in presence and absence of cobalt deuteroporphyrin are about $425 \mathrm{~nm}$, revealing that the luminophor in both chemiluminescence reactions are the excited state 3 -aminophthalate anions of luminol ${ }^{9}$.

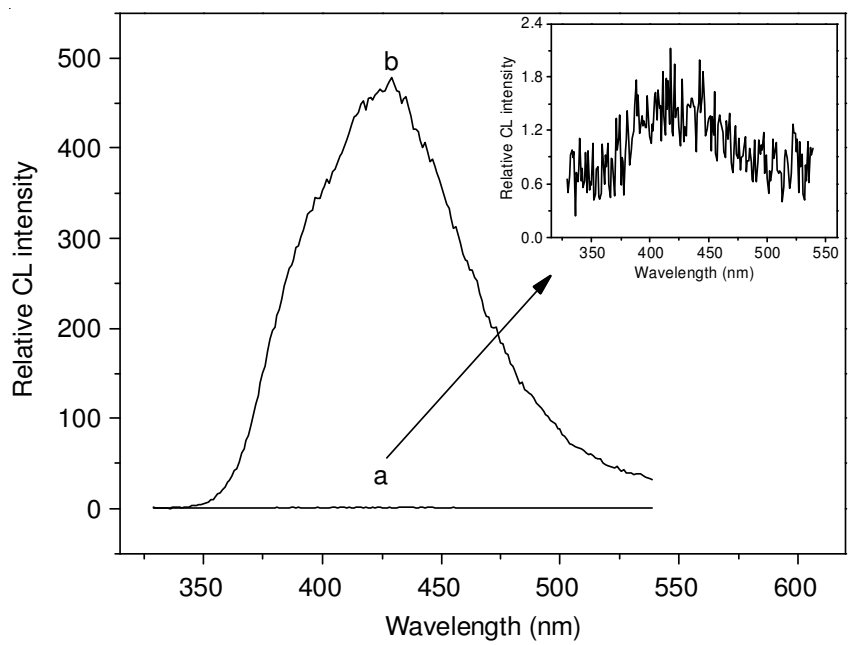

Fig. 5. Kinetic characteristics of the luminol- $\mathrm{H}_{2} \mathrm{O}_{2}$-cobalt deuteroporphyrin chemiluminescence system; (a) luminol- $\mathrm{H}_{2} \mathrm{O}_{2}-\mathrm{NaOH}$; (b) luminol$\mathrm{H}_{2} \mathrm{O}_{2}$-cobalt deuteroporphyrin- $\mathrm{NaOH}$

Although the mechanism of this reaction is not completely understood, it is well known that in metalloporphyrin-containing peroxidase enzymes and metalloporphyrins catalyzed luminol- $\mathrm{H}_{2} \mathrm{O}_{2}$ chemiluminescence systems, the excited state 3 -aminophthalate anion of luminol is generated from the reaction of luminol with high-valent oxo-metalloporphyrin intermediates, which are formed in the reaction between metalloporphyrins and hydrogen peroxide ${ }^{11,20}$. Thus, we suppose here the formation of high-valent oxidizing intermediates of cobalt deuteroporphyrin that are formal "Co (IV)" species is the key step in this reaction. The Co (IV) intermediate is reactive and quickly reduced by cobalt deuteroporphyrin to a formal dimeric Co (III)-porphyrin $\pi$-cation radical complex (Scheme-II), which is supposed to be responsible for the initiation of the reaction sequence leading finally to the oxidation of luminol and the generation of exited 3-aminophthalate anions ${ }^{20,21}$. Diethylstilbestrol is thought to be an antiradical molecule, which will compete with luminol for the cobalt porphyrin-derived oxidizing intermediates and any other oxidant species present in this system ${ }^{22}$. The main pathway for the disappearance of the generated diethylstilbestrol aryloxy radicals is its dismutation, leading to the formation of a stable diethylstilbestrol quinone and the suppression of the light emission.

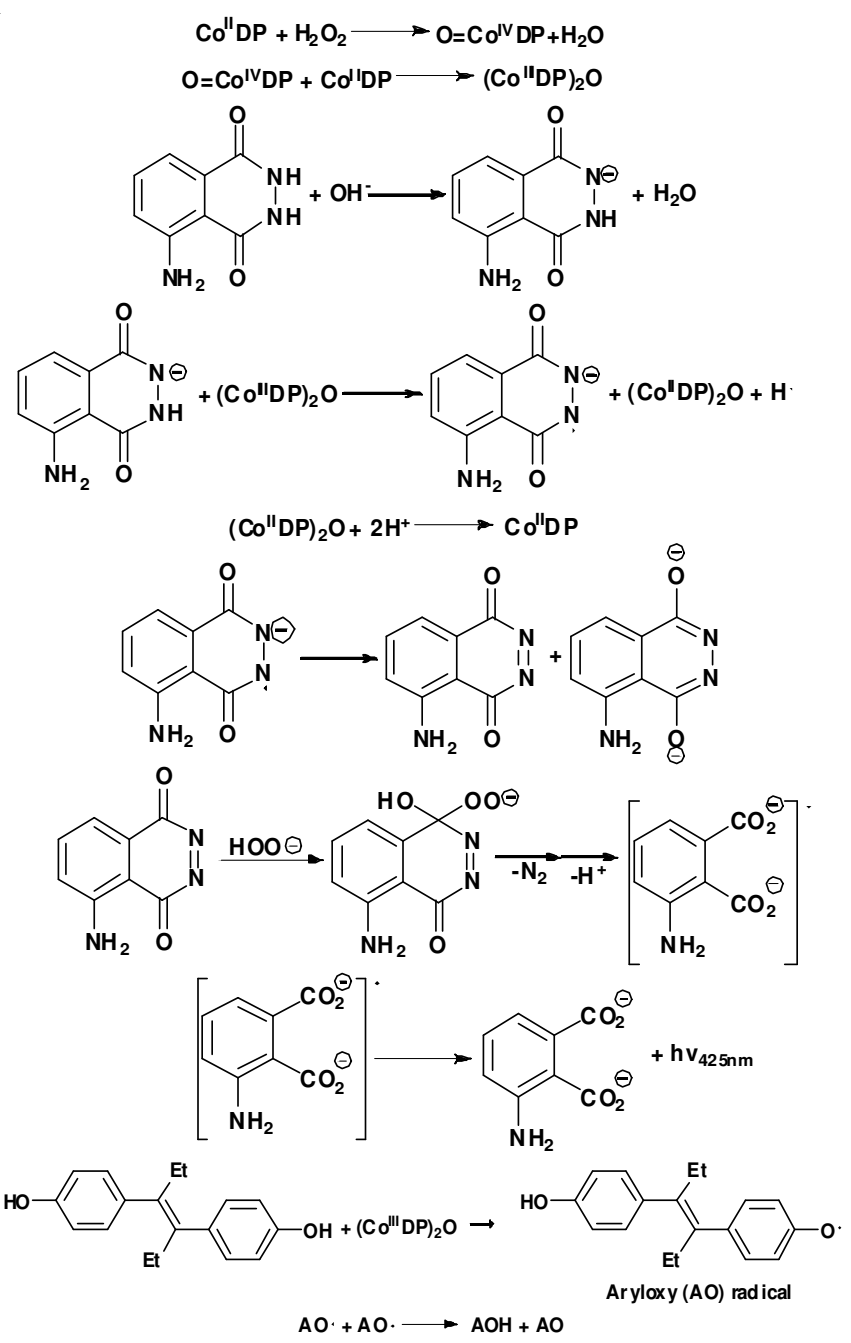

Scheme-II: Scheme of diethylstilbestrol detection in cobalt deuteroporphyrin catalyzed luminol- $\mathrm{H}_{2} \mathrm{O}_{2}$ chemiluminescence system

\section{Conclusion}

It could be concluded from above discussion that the inhibition of diethylstilbestrol to cobalt deuteroporphyrin catalyzed luminol- $\mathrm{H}_{2} \mathrm{O}_{2}$ chemiluminescence reaction is attributed to the competition of antiradical diethylstilbestrol with luminol for cobalt deuteroporphyrin-derived high-valence porphyrin intermediates. Based on this chemiluminescence reaction, a sensitive and specific FI-CL method was developed for the rapid determination of diethylstilbestrol. The optimization of the experimental parameters has been carried out. This chemiluminescence system could be successfully used for the determination of the dosage of diethylstilbestrol in pharmaceutical product samples with a detection limit of $3.83 \times 10^{-10}$ $\mathrm{g} \mathrm{mL}^{-1}$.

\section{REFERENCES}

1. J. Wang, H. Ye, Z. Jiang, N. Chen and J. Huang, Anal. Chim. Acta, 508, 171 (2004).

2. Y. Zhao, Y. Liang, J. Qian, L. Li and S. Wang, Anal. Lett., 42, 216 (2009).

3. J. Odum and P.A. Lefevre, Toxicol. Sci., 68, 147 (2002).

4. J. Shamash, T. Powles, S.J. Sarker, A. Protheroe, N. Mithal, R. Mills, R. Beard, P. Wilson, N. Tranter, N. O'Brien, S. McFaul and T. Oliver, Br. J. Cancer, 104, 620 (2011).

5. E.N. Barkatina, S.V. Volkovich, O.N. Venger, V.I. Murokh, N.D. Kolomiets and O.V. Shulyakovskaya, J. Anal. Chem., 56, 740 (2001). 
6. M.J. López de Alda and D. Barceló, J. Chromatogr. A, 892, 391 (2000).

7. S. Kanimozhi, C. Basheer, K. Narasimhan, L. Liu, S. Koh, F. Xue, M. Choolani and H.K. Lee, Anal. Chim. Acta, 687, 56 (2011).

8. M.J. López de Alda and D. Barceló, J. Chromatogr. A, 938, 145 (2001)

9. F.J. Lara, A.M. García-Campaña and J. Aaron, Anal. Chim. Acta, 679, 17 (2010).

10. L. Wang, Y. Tang and Y. Liu, J. Pharm. Anal., 1, 51 (2011).

11. S. Xu, W. Liu, B. Hu, W. Cao and Z.L. Liu, J. Photochem. Photobiol. Chem., 227, 32 (2012).

12. T. Yamaguchi, K. Tsukamoto, O. Ikeda, R. Tanaka, T. Kuwabara and K. Takahashi, Electrochim. Acta, 55, 6042 (2010).

13. J.F. van Staden and R.I. Stefan-van Staden, Talanta, 80, 1598 (2010).

14. D. Wu, Y. Han, Q. Wei, Y. Zhao, K. Mao, Y. Cai, R. Li and Y. Dai, Luminescence, 26, 629 (2011).
15. W. Zhou, B. Hu and Z. Liu, Appl. Catal. A, 358, 136 (2009).

16. R.K. Dinello and D.H. Dolphin, J. Org. Chem., 46, 3498 (1981).

17. C. Sun, B. Hu, W. Zhou, S. Xu and Z.L. Liu, Ultrason. Sonochem., 18, 501 (2011).

18. E.S. Ribeiro, S.L.P. Dias, Y. Gushikem and L.T. Kubota, Electrochim. Acta, 49, 829 (2004).

19. H. Chen, F. Gao, R. He and D. Cui, J. Colloid Interf. Sci., 315, 158 (2007).

20. E.L. Bastos, P. Romoff, C.R. Eckert and W.J. Baader, J. Agric. Food Chem., 51, 7481 (2003).

21. J. Lee, J.A. Hunt and J.T. Groves, J. Am. Chem. Soc., 120, 6053 (1998).

22. I. Biryol, B. Salci and E. Erdik, J. Pharm. Biomed. Anal., 32, 1227 (2003). 